\title{
AVALIAÇÃo do POTENCAL DE PRODUÇÃO DO “PEQUIZEIRO-ANÃO" SOB CONDIÇÕES NATURAIS NA REGIÃO SUL DO ESTADO DE MINAS GERAIS ${ }^{1}$
}

\author{
DIJALMA BARBOSA DA SILVA ${ }^{2}$; NILTON TADEU V. JUNQUEIRA ${ }^{3}$; JOSÉ ANTÔNIO DA SILVA ${ }^{4}$; \\ AILTON VÍTOR PEREIRA ${ }^{3}$; ANTÔNIO SALVIANO ${ }^{5}$; GIL DONIZETE JUNQUEIRA ${ }^{6}$
}

\begin{abstract}
RESUMO - O pequizeiro (Caryocar spp. - Caryocaraceae) é uma planta nativa do Cerrado e da Amazônia, cujo fruto é muito rico em óleo e proteína, e bastante apreciado pelos povos que vivem nestes ecossistemas. O objetivo desse trabalho foi avaliar o potencial de produção do "pequizeiro-anão", (Caryocar brasiliense subsp. intermedium), em seu habitat. Foram realizadas duas prospecções botânicas na região Sul do Estado de Minas Gerais, em 1997 e 1998, em áreas de vegetação de cerrado, nas proximidades do município de Ingaí-MG, onde se observou a ocorrência de pequizeiro de porte baixo. Foi observado que os frutos apresentam deiscência e grande heterogeneidade em relação ao número de frutos/planta. Nas plantas com tronco, encontraram-se até 86 frutos/planta e, nas sem tronco, até 16 frutos/planta. A época de maturação dos frutos concentra-se nos meses de fevereiro e março. $O$ fruto de cor esverdeada e polpa amarelo-alaranjada possui em média duas sementes/endocarpo, com peso médio de $8 \mathrm{~g}$. Em plantios realizados no Distrito Federal, foi observado que as plantas de "pequizeiro-anão", oriundas de sementes, iniciaram a frutificação com altura de $60 \mathrm{~cm}$, aos 18 a 24 meses após o plantio, evidenciando que são também precoces. O "pequizeiro-anão" apresenta potencial para sua exploração em cultivos comerciais e em programas de melhoramento genético.
\end{abstract}

Termos para a indexação: Caryocar brasiliense subsp. intermedium, Caryocaraceae, cerrado, pequi, piqui.

\section{DWARF “PEQUI" PRODUCTION POTENTIAL EVALUATION UNDER NATURAL CONDITIONS IN SOUTHERN MINAS GERAIS STATE}

\begin{abstract}
The pequi tree (Caryocar spp. - Caryocaraceae), a wild specie of Brazilian savannah and Amazon region, is an edible fruit for people living in these ecosystems. The "dwarf pequi tree" (Cariocar brasiliense subsp. intermedium), has a restricted occurrence in some parts of Brasilian savanna which is an incorporated process to arable farm, treating the survival of this specie. The objective of this work was to evaluate the production potencial of "dwarf pequi tree" in its natural habitat. The fruits can be harvested from February to March. In the plant with and without trunk there are up to 86 and 16 fruits per plant respectively. Each fruit has 2 dark yellow mesocarp and each mesocarp weighs $8 \mathrm{~g}$. One year old seedlings of dwarf pequi plants raised from seeds started bearing fruits with $60 \mathrm{~cm}$ height 18 to 24 months after field planting in Federal District of Brazil, showing its early ripening character. The data obtained in these studies indicate that dwarf pequi has a great potential for commercial and genetic improvement program to reduce the common pequi tree height.
\end{abstract}

Index terms: Caryocar brasiliense subsp. intermedium, Caryocaraceae, savanna

O pequizeiro (Caryocar spp. - Caryocaraceae) é uma planta nativa do Cerrado e da Amazônia, cujo fruto é muito rico em óleo e proteína, e bastante apreciado pelos povos que vivem nestes ecossistemas. Ferreira et al. (1988) encontraram teores de óleo de $61,79 \%$ e $42,2 \%$ e teores de proteína de $6,71 \%$ e $24,6 \%$, respectivamente, na polpa e na amêndoa de frutos provenientes da região de Cerrado, destacando, ainda, a riqueza destes frutos em relação a vários elementos minerais, quando comparados com diversas frutas economicamente cultivadas. Silva et al. (1994) encontraram $20000 \mathrm{mcg}$ de vitamina A e $463 \mathrm{mcg}$ de vitamina $B_{2}$ na polpa de frutos de pequi do Cerrado. Além do uso alimentar em pratos típicos da região, o óleo da polpa dos frutos possui propriedades medicinais (Salles et. al., 1997).

Segundo Prance e Silva (1973), quinze espécies e cinco subespécies de pequizeiro foram descritas até 1973. Distribuídas na faixa tropical do continente americano, apenas quatro dessas espécies não ocorrem no Brasil. A espécie de maior presença na região do Cerrado é $C$. brasiliense Camb., dividida em duas subespécies: $C$. brasiliense subsp. brasiliense de porte arbóreo com ampla distribuição e $C$. brasiliense subsp. intermedium, de porte arbustivo com ocorrência restrita a algumas partes deste ecossistema. O "pequizeiro-anão", representado por $C$.

1 (Trabalho 223/2000). Recebido: 06/10/2000. Aceito para publicação: 30/08/2001.

2 Eng. Agr., M. Sc., Embrapa - Centro Nacional de Recursos Genéticos e Biotecnologia (CENARGEN), SAIN Parque Rural, Av. W/5 Norte (final). C. postal 0232 CEP 70770900 Brasília, DF. Email dijalma@cenargen.embrapa.br

3 Eng. Agr., Ph.D. Embrapa - Centro de Pesquisa Agropecuária dos Cerrados (CPAC). Caixa Postal 08223 CEP 73301 970. Planaltina, DF.

4 Biólogo., Embrapa - Centro de Pesquisa Agropecuária dos Cerrados (CPAC). Caixa Postal 08223 CEP 73301 970. Planaltina, DF.

5 Eng. Agr., M.Sc.,. Embrapa - Centro de Pesquisa Agropecuária dos Cerrados (CPAC). Caixa Postal 08223 CEP 73301970. Planaltina, DF.

6 Estudante da UFLA, Campos Universitário. Caixa Postal 37, CEP 37200 000. Lavras, MG. 
brasiliense subsp. intermedium, também denominado pequirasteiro ou pequi-de-moita, possui folhas planas, não rugosas, com pedicelos e pedúnculos glabros ou pouco pubescentes. A face superior da folha é geralmente glabra, podendo, no entanto, apresentar pêlos longos, duros e grossos, esparsamente distribuídos em sua superfície, à semelhança do que ocorre na face inferior. As plantas apresentam hábito de crescimento arbustivo do tipo sufrutecente com caule aparente ou não.

A incorporação recente das áreas de cerrado à agricultura brasileira e a forma extrativista como o pequi tem sido explorado representam uma grande ameaça à sobrevivência dessas espécies, principalmente para o pequizeiro-anão, devido a sua baixa freqüência e distribuição restrita. Assim, num futuro próximo, poderá haver uma redução considerável na oferta deste fruto e conseqüente elevação de preço.

O objetivo deste trabalho foi avaliar o potencial de produção do "pequizeiro-anão", em seu habtat, a percentagem de germinação de suas sementes e o comportamento ex situ da planta.

Foram realizadas duas prospecções botânicas à região Sul do Estado de Minas Gerais, em 1997 e 1998, em áreas de vegetação de Cerrado do tipo Campo sujo, nas proximidades do município de Ingaí-MG, localizado a $21^{\circ} 24^{\prime} 4^{\prime \prime}$ de latitude Sul e $44^{\circ} 55^{\prime} 2^{\prime \prime}$ de longitude Oeste, com 951 metros de altitude (IBGE, 1990), clima do tipo temperado propriamente dito, mesotérmico de inverno seco ( $\mathrm{Cwb}$ ), segundo a classificação de Köppen (Brasil, 1969), onde se observou a ocorrência de uma população de pequizeiros de porte baixo.

Avaliaram-se a altura da planta, diâmetro da copa, número de hastes por planta, número de frutos por planta, número de sementes/endocarpo por fruto, peso das sementes/endocarpo, época de florescimento e frutificação, cor do fruto e da polpa e a densidade de plantas de "pequizeiro-anão" em seu habitat. Para isso, foi delimitada uma área de um hectare, onde supostamente havia maior densidade de plantas de porte baixo. Foram coletadas sementes para avaliação do poder germinativo, e 200 mudas

TABELA 1 - Densidade de plantas/ha, altura da planta, diâmetro da copa, $\mathrm{n}^{\circ}$ de hastes/planta, $\mathrm{n}^{\circ}$ de frutos/planta, $\mathrm{n}^{\circ}$ de sementes / endocarpo / fruto e peso do endocarpo de "pequizeiro-anão", no município de Ingaí, Sul do Estado de Minas Gerais.

\begin{tabular}{|c|c|c|c|}
\hline \multirow{2}{*}{ V ariáveis } & \multirow{2}{*}{ Tipo Agronômico } & \multicolumn{2}{|c|}{ A no } \\
\hline & & 1997 & 1998 \\
\hline \multirow{3}{*}{$\begin{array}{c}\text { Densidade de } \\
\text { plantas } / \text { ha }\end{array}$} & & & \\
\hline & Sem tronco & 95 & 95 \\
\hline & Com tronco & 19 & 19 \\
\hline \multirow[t]{2}{*}{ A ltura da planta $(\mathrm{m})$} & Sem tronco & 0,3 a 0.7 & 0,3 a 0,7 \\
\hline & Com tronco & 0,6 a 1,5 & 0,6 a 1,5 \\
\hline \multirow[t]{2}{*}{ Diâm etro da copa $(m)$} & Sem tronco & - & - \\
\hline & Com tronco & 0,8 a 1,7 & 0,8 a 1,7 \\
\hline \multirow[t]{2}{*}{$\mathrm{N}^{\circ}$ de hastes/planta } & Sem tronco & 2 a 8 & 2 a 8 \\
\hline & Com tronco & - & - \\
\hline \multirow[t]{2}{*}{$\mathrm{N}^{0}$ de frutos/planta } & Sem tronco & $4,3(1-16)^{* *}$ & $2,9(1-10)$ \\
\hline & Com tronco & $28,0(5-86)$ & $21,0(3-45)$ \\
\hline \multicolumn{4}{|l|}{$\mathrm{N}^{0} \mathrm{de}$} \\
\hline \multirow{2}{*}{$\begin{array}{c}\text { sementes/endocarpo } \\
\text { fruto }\end{array}$} & Sem tronco & 2,0 & 2,0 \\
\hline & Com tronco & 2,0 & 2,0 \\
\hline \multirow[t]{2}{*}{ Peso do endocarpo (g) } & Sem tronco & 8 & 8 \\
\hline & Com tronco & 8 & 8 \\
\hline
\end{tabular}

* Em 1997 e 1998, 8 e 18 plantas não produziram frutos, respectivamente

** Amplitude observada 


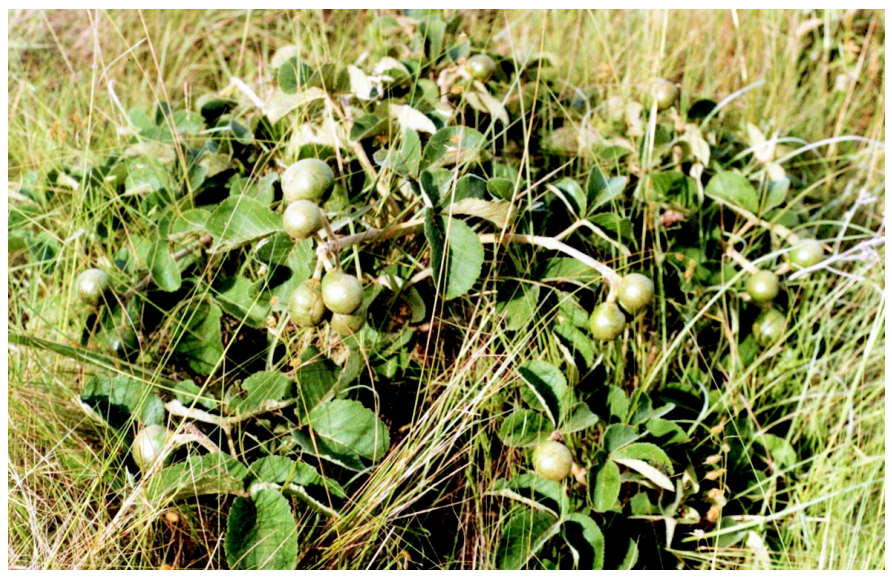

FIGURA 1 - Planta de "pequizeiro-anão" sem tronco (pequi-demoita), em seu habitat, na região Sul do Estado de Minas Gerais.

provenientes destas sementes foram plantadas no Distrito Federal.

De acordo com a chave de identificação de subespécies de C. brasiliense (Prance e Silva, 1973), foram identificadas 114 plantas de C. brasiliense subsp. Intermedium, na área delimitada. Devido às variações fenotípicas observadas, as plantas foram estratificadas em função do tipo agronômico (Tabela 1). Assim, das 114 plantas encontradas na área de um hectare, 95 apresentaram porte arbustivo em forma de moitas, com duas a oito hastes, oriundas de um tipo de "tronco subterrâneo" e altura de 0,3 a $0,7 \mathrm{~m}$ (Figura 1), e 19 plantas apresentaram pequeno porte (Figura 2), com tronco lenhoso e grosso na base, com circunferência de 0,2 a $0,5 \mathrm{~m}$, altura de 0,6 a $1,5 \mathrm{~m}$, e diâmetro de copa de 0,8 a $1,7 \mathrm{~m}$.

Não houve alteração na densidade de plantas/ha, altura da planta, diâmetro da copa, número de hastes por planta, número de sementes por fruto e peso do endocarpo/semente no período do estudo. Em 1998, houve redução no número de frutos/planta. O florescimento ocorreu no período de setembro a outubro e a maturação dos frutos de fevereiro e março. Observou-se que os frutos apresentam deiscência e que há grande heterogeneidade em relação ao número de frutos/planta, mas o peso do endocarpo foi semelhante aos valores encontrados por Ferreira et al. (1988) e Silva et al., (1994), em pequizeiros comuns da região do Cerrado, C. brasiliense Camb. Em plantas de porte arbustivo sem tronco, foram observados até 16 frutos por planta e, em plantas com tronco, com um metro de altura e 1,5 m de diâmetro de copa, até 86 frutos. O fruto possui cor da casca esverdeada e cor da polpa amarelo-alaranjada semelhantes ao do pequizeiro comum, relatado por Ferreira et al. (1988) e Silva et al. (1994). As sementes de "pequizeiro-anão", sem tratamentos para quebra de dormência, apresentaram 30\% de germinação no período de um ano, em sementeira de areia. Resultados semelhantes foram obtidos por Dombroski (1997), para sementes de pequizeiros comuns coletadas na região Sul de Minas Gerais, próximo ao município de Ingaí-MG. Nos plantios realizados no Distrito Federal, foi observado que as plantas de "pequizeiro-anão", oriundas de sementes, iniciaram a frutificação com altura de $60 \mathrm{~cm}$, à semelhança do que ocorre em seu habitat, aos 18 a 24 meses após o plantio, evidenciando que, além do porte baixo, são também precoces, pois o pequizeiro comum da região do Cerrado inicia a

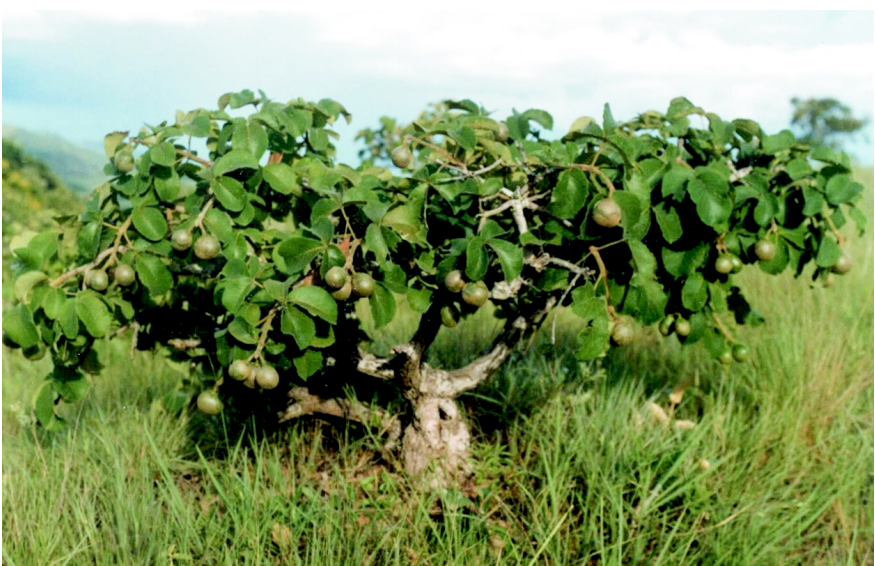

FIGURA 2 - Planta de "pequizeiro-anão" com tronco, em seu habitat, na região Sul do Estado de Minas Gerais.

frutificação aos cinco anos após o plantio.

O porte baixo das plantas do "pequizeiro-anão" é uma característica desejável, que favorece a colheita, tratos fitossanitários e culturais, e permite o plantio de uma maior densidade de plantas por área, enquanto a sua precocidade permitirá um retorno mais rápido de investimentos para os agricultores.

Baseados nesta avaliação, podemos concluir que o "pequizeiro-anão" apresenta um grande potencial a ser explorado em cultivos comerciais e em programas de melhoramento genético. Por isso, as atividades de coleta, caracterização, in situ e ex situ, e a seleção de matrizes potenciais de "pequizeiro-anão" devem receber prioridade dos órgãos de pesquisa, preservação ambiental e extensão rural e de técnicos, ecologistas e agricultores.

Futuramente, o "pequizeiro-anão" poderá ser utilizado em programas de melhoramento visando à redução do porte do pequizeiro comum, por meio do cruzamento ou, simplesmente, como porta-enxerto com características ananicantes. Entretanto, é importante ressaltar que muito pouco se conhece sobre o pequizeiro-comum e o "pequizeiro-anão", podendo haver dificuldades num programa de melhoramento.

\section{REFERÊNCIAS BIBLIOGRÁFICAS}

BRASIL. Ministério da Agricultura. Normas climatológicas. Rio de Janeiro, 1969. v. 3. 99p.

DOMBROSKI, J. L. D. Estudos sobre a propagação do pequizeiro ( Cariocar brasiliense Camb.). 1997. 78f. Dissertação (Mestrado em Agronomia) - Universidade Federal de Lavras, Lavras, 1997.

IBGE. Departamento de Cartografia. Listagem de cidades e vilas do Brasil. Brasília, 1990. p. 23.

PRANCE, G. T.;SILVA, M. F. Caryocaraceae .New York: Hafner, 1973. 75p. (Flora Neotrópica, Monograph n. 12). 
FERREIRA, F. R.; BIANCO, S.; DURIGAN, J. F.; BELINGIERE, P. A. Caracterização física e química de frutos de pequi. In: CONGRESSO BRASILEIRO DE FRUTICULTURA, 9., 1987. Campinas, SP. Anais... Campinas: Sociedade Brasileira de Fruticultura, 1988. p. $643-646$.

SILVA, J. A.; SILVA. D. B. da; JUNQUEIRA, N. T. V.; ANDRADE,
L. R. M. Frutas nativas dos cerrados. Planaltina: EMBRAPACPAC/Brasília: EMBRAPA-SPI, 1994. 166p.

SALLES, A. H.; REIS. G. M. C. L.; ZURLO. M. A. Horto Medicinal do Cerrado. 2. ed. rev., ampl. - Brasília: Jardim Botânico de Brasília, 1997.33p. 